\title{
BMJ Open Animal-related injuries and fatalities: evidence from a large-scale population- based cross-sectional survey in rural Bangladesh
}

\author{
Md Al Amin Bhuiyan (D) , ${ }^{1}$ Priyanka Agrawal, ${ }^{2}$ Shirin Wadhwaniya, ${ }^{2}$ Qingfeng Li (D) , ${ }^{2}$ \\ O Alonge, ${ }^{2}$ AKM Fazlur Rahman, ${ }^{1}$ Aminur Rahman ${ }^{1}$
}

To cite: Bhuiyan MAA, Agrawal P, Wadhwaniya S, et al. Animal-related injuries and fatalities: evidence from a large-scale population-based cross-sectional survey in rural Bangladesh. BMJ Open 2019;9:e030039. doi:10.1136/ bmjopen-2019-030039

- Prepublication history and additional material for this paper are available online. To view these files, please visit the journal online (http://dx.doi. org/10.1136/bmjopen-2019030039).

Received 26 February 2019 Revised 04 September 2019 Accepted 24 September 2019

Check for updates

(C) Author(s) (or their employer(s)) 2019. Re-use permitted under CC BY-NC. No commercial re-use. See rights and permissions. Published by BMJ.

${ }^{1}$ Centre for Injury Prevention and Research, Bangladesh (CIPRB), House B162, Road 23, New DOHS, Mohakhali, Dhaka 1206, Bangladesh

${ }^{2}$ Johns Hopkins International Injury Research Unit,

Department of International Health, Johns Hopkins Bloomberg School of Public Health, $615 \mathrm{~N}$. Wolfe Street, Baltimore, Maryland, USA

Correspondence to Dr Md Al Amin Bhuiyan; al_amin_prime@yahoo.com

\section{ABSTRACT}

Objective This study determines the magnitude and pattern of animal-related injury mortalities and morbidities in rural Bangladesh.

Design and setting $A$ cross-sectional survey was conducted in 51 Unions of 7 subdistricts of Bangladesh from June 2013 to September 2013.

Participants A total of approximately 1.17 million individuals across all age and gender profiles were included in the survey. The participants had to be residents of the seven subdistricts and have provided consent to participate in the study.

Primary and secondary outcome measures Animalrelated injury characteristics and demographic information was collected in the study. Frequency, proportion and $95 \%$ Cls of variables such as type of animal, type of animal attack, activity of the person prior to attack and the seasonality of the injury were reported. Data was then statistically analysed for associations between injury and sociodemographic characteristics.

Results The incidence rate of fatal and non-fatal animalrelated injuries across all ages were $0.7(95 \% \mathrm{Cl} 0.4$ to 1.4) and $1635.3(95 \% \mathrm{Cl} 1612.0$ to 1658.0$)$ per 100000 populations, respectively. Non-fatal animal-related injury rates were highest among adults 18 years and older (1820.6 per 100000 population (1777.2 to 1865.1)), and in males across all age groups. The most common animal injury was wasp/hornet/bee sting (49\%), followed by cow/ buffalo (25\%), dog bite (9\%) and snake bites (9\%).

Conclusions Animal-related injuries are an important public health issue in rural Bangladesh. The incidence of animal-related morbidities was found high in the study area. Males, school-going and productive age groups were at high risk. Immediate attention should be given to prevent these events.

\section{INTRODUCTION}

Animal injuries are becoming an increasing public health issue among children and adults. Animal attacks cause a large number of injuries and deaths and lead to significant medical and social consequences worldwide. ${ }^{1}$ About $50 \%$ of all individuals experience at least one animal bite in their lifetime, especially during childhood. ${ }^{2}$ Animal injuries are
Strengths and limitations of this study

- The study was based on a large-scale population covering 1.17 million people and thus provides more accurate estimates of animal-related injury in rural Bangladesh.

- Even though animal-related injuries are locally and regionally variable, the findings from this study can be conservatively generalised to other parts of the country and other low- and middle-income countries with similar age group, gender and socioeconomic status distributions.

- The recall period for non-fatal injuries in this study was 6 months and reported rates have been annualised under the assumption that rates were consistent throughout the year - which is a major limitation of this study.

- The study was conducted in rural Bangladesh and findings might not be generalisable to urban parts of the country where exposure and risk factors vary.

most commonly due to but not limited to snakes, dogs, cats and monkeys, accounting for more than 55000 deaths worldwide. ${ }^{3}$

The health impacts of an animal injury depend on the type and health of the animal, the size and health of the human victim and accessibility to treatment. ${ }^{3}{ }^{4}$ Approximately 90\% injuries are from domestic animals and $70 \%$ of those are from pets. ${ }^{25}$ Animalrelated injuries can also be caused by butting, impaling or stepping on an animal. ${ }^{6}$ Apart from these types of animal attacks, snake bites are often associated with high mortality and morbidity and are considered to be an one of the most common occupational injuries among the poor and vulnerable rural people in South East Asia. ${ }^{7}$ Fatal anaphylactic reactions are also seen due to some stinging insects such as swarming social hornets, bees, ants, scorpions and wasps. ${ }^{4}$

However, animal-related injuries have still not received much attention in low- and 
middle-income countries. ${ }^{4}$ Bangladesh has the third highest mortality rate among rabies-endemic countries and children under 15 years of age from poor rural communities are affected the most. ${ }^{9}$ Snake bites are also a common health problem in Bangladesh's rural community, where the rate was $623.4 / 100000$ person years. ${ }^{10}$ In 2007, surveillance system of the Directorate General of Health Services found snake bite was the leading cause of mortality during flood disaster. Unlike other injuries, the exact burden of animal injuries in Bangladesh is quite difficult to estimate because of poor reporting systems and lack of population level data for both fatal and non-fatal animal injury events. ${ }^{7} 910$ Therefore, it is important to explore the present epidemiological status of animal-related injury mortalities and morbidities in Bangladesh to implement injury prevention programmes across the country. A subset of the sociodemographic and injury-related information collected as part of a drowning prevention project 'Saving of Lives from Drowning (SoLiD) in Bangladesh' was used to describe the epidemiology and associated risk factors of animal-related injuries in rural Bangladesh in this particular study.

\section{METHODS}

\section{Study design, area and population}

A baseline survey was conducted in 2013 to collect epidemiological information on fatal and non-fatal injuries, as part of a drowning prevention intervention study, SoLiD. ${ }^{11} 12$ The census was held in seven subdistricts (upazilas) of rural Bangladesh - Matlab North, Matlab South, Daudkandi, Chandpur Sadar, Raiganj, Sherpur Sadar and Monohardi and covered approximately 1.17 million people in 51 Unions from these selected areas. These subdistricts were chosen purposively as a higher rate of childhood drowning was found there.

\section{Data collection tools and technique}

Information was collected on fatal and non-fatal injury outcomes (including animal injuries) from household heads or adult respondents (above 18 years of age) by face-to-face interview using pretested structured questionnaires. Data collection was conducted in two stages.

In the first stage, general demographic information on all household members was collected along with history of any injury in the past 6 months and deaths in the past 1 year. Injury was operationalised as 'any external harm resulting from an assault, fall, cut, burn, animal injury, poisoning, transportation of goods and persons, operating machinery, blunt objects, suffocation and (near) drowning resulting in the loss of one or more days of normal daily activities, schools or work'. In the second stage of data collection, detailed information was obtained on any injury-related mortality and morbidity that was reported during the first round of data collection. Each specific injury mechanism had a specific module pertaining to relevant circumstances (see online supplementary appendix). The methods have been described in detail elsewhere. ${ }^{13}$

\section{Quality control of data}

To maintain the quality of data, trained supervisors were appointed. Around 10\% of interviews were re-observed that were conducted by the data collectors, $10 \%$ of the collected data were rechecked and $2 \%$ of the households were re-interviewed by the supervisors. All the data were rechecked for inconsistencies. Also, field managers and coordinators were asked to recheck the data for inconsistencies. For inconsistent data, the concerned data collector was asked to revisit that household to collect the correct information.

\section{Patient and public involvement}

During the development of the survey tools, measurements and the study protocol, several meetings were held with the local partners, government officials and researchers in Bangladesh to discuss the needs and gaps of the injury deaths and health survey planned for rural Bangladesh. The instruments were then modified according to the needs of the Bangladeshi population as recommended in the meeting. This study examined the participants (household head) in their home environment and did not enrol any clinical patients.

\section{Statistical method and analyses}

For the purposes of this paper, the analysis was restricted to all animal injury-related events from the baseline census. Descriptive statistical analyses were conducted for fatal and non-fatal animal-related injury outcomes and were estimated as counts, proportions and 95\% CIs across sociodemographic factors such as age, gender, occupation, educational level and socioeconomic status. Injury characteristics such as the animal, injury type, activity of the person prior to attack and the seasonality of the animal-related injury were also calculated. Fatal and non-fatal animal-related injury rates were calculated per 100000 population per year. Since the recall period for non-fatal injuries was 6 months, the rates were annualised by multiplying by a factor of 2 under the assumption that the rate was consistent throughout the year.

Determinants of non-fatal animal-related injury outcomes were modelled as ORs comparing levels of independent variables using logistic regressions. The variables age, gender, occupation, education level, socioeconomic status, marital status and subdistrict were included as variables in the regression model. As these variables are known risk factors for animal injury from past research, all variables were included in the final multivariable regression model. Results from both bivariable and multivariable analyses are presented. Associations were not compared for fatal injury events as only eight deaths were recorded. Results were considered significant at a $p$ value of less than 0.05 . 
A population-level injury severity index was developed based on indicators like anatomical and physiological profiles of an injury, post-injury immobility, post-injury hospitalisation, surgical treatment, post-injury disability, number of days an individual required assistance and the number of days lost at work or school - information collected as part of the baseline census. ${ }^{14}$ A linear combination of a set of variables were accounted for to come up with a custom index of severity. The injury severity indices for all non-fatal injuries were calculated and segregated into tertiles of low, medium and high severity. All analyses were conducted on Stata quantitative analysis software (StataCorp 15.1).

\section{RESULTS}

In the SoLiD baseline survey, a total population of approximately 1.17 million people were studied across the seven subdistricts of Bangladesh. (table 1) Overall, the majority population was females $(51.5 \%, \mathrm{n}=601919), 18$ years of age and above years of age $(60 \%)$, had no education or received at least primary level education $(60 \%)$, were married (49\%, $\mathrm{n}=576352)$, unemployed $(78 \%)$ and were either retired, unemployed or housewives $(35 \%, \mathrm{n}=408$ 583 ). Around 30\% (353 531) had received secondary and higher education. The respondents by subdistrict was Matlab North (22.7\%), Matlab South (18\%), Chandpur Sadar (11\%) of Chandpur district, Sherpur Sadar (19.5\%) of Sherpur district, Monohardi (17.5\%) of Narsingdi district and Raiganj (8.9\%) of Sirajganj district. Detailed characteristics of the sample population have also been described in previous work. ${ }^{13}$

\section{Characteristics of fatal and non-fatal animal-related injury}

A total of eight fatal animal-related injury events were recorded in this census, and the mortality rate in this population was 0.7 per 100000 population (95\% CI 0.4 to 1.4). Animal-related injury mortality rates were predominantly seen in males and were higher than deaths in females. Children 1 to 5 years of age had the highest rates of fatal animal injuries 1.1 per 100000 population (95\% CI 0.2 to 6.3 ). Mortality rates were also higher among those who did not receive any formal education, involved in agriculture, never-married and the lowest wealth quantile. Mortality rates were highest in the Sherpur subdistrict among all subdistricts surveyed (1.3 per 100000 population) (table 1 ).

There were 9563 animal-related incidents among the population surveyed, with the morbidity rate of 1635.3 injuries per 100000 population (95\% CI 1612.0 to 1658.0). The frequency of non-fatal animal-related injuries rates was highest among males 1837.3 per 100000 population (95\% CI 1803.0 to 1873.0), and among the people 18 years and older 1820.6 per 100000 population (95\% CI 1777.2 to 1865.1 ). Rates of non-fatal animalrelated injuries were higher among those with no formal education 1132.4 per 100000 populations (95\% CI 1095.0 to 1171.0), in those who practiced agriculture, among the married and in the low socioeconomic status (SES) quintile (table 1). The highest non-fatal animal-related injury rates were seen in Raiganj at 2648.6 per 100000 populations (95\% CI 2553.0 to 2748.0), followed by Monohardi and Sherpur upazilas.

Most non-fatal animal injuries occurred in the monsoon season, with a peak between June and August (figure 1).

Over $65 \%$ of the animal-related injuries occurred without any provocation and $67 \%$ of injuries occurred by stinging. The highest proportion of animal injuries was caused by the hornets/wasps/bees $(51 \%)$, followed by cow/buffalo (25\%) (figure 2).

Most non-fatal animal-related injuries had low severity $(81.6 \%)$ and only $6.1 \%$ cases were severely injured (table 2).

\section{Determinants of regression for non-fatal animal-related injury outcomes}

Females had $30 \%$ lower odds of animal injuries compared with males (OR $0.7,95 \%$ CI 0.6 to 0.7 ) (table 3). Children and adults 18 years and above were at highest risk of animal-associated injuries compared with all other age groups (OR $0.2,95 \%$ CI 0.1 to 0.3 ; OR $0.8,95 \%$ CI 0.6 to 0.9 and OR $1.1,95 \%$ CI 0.9 to 1.3 ) (table 3). Higher education was associated with lower odds of animal-related injuries. People with secondary education had $20 \%$ lesser odds of having animal-related injuries than those with no education (OR 0.8, 95\% CI 0.7 to 0.9 ) (table 3 ). People involved in agriculture had the highest odds of animal-related injuries than any other occupations. SES had an inverse relationship with odds of animal-related injuries, higher the SES, lower the odds of having an animal sting related injury. Raiganj had a 3.6 times (95\% CI 3.44 to 3.9) (table 3) higher risk of having animal stings among its residents when compared with Matlab North.

\section{DISCUSSION}

Animal-related injuries are an important cause of morbidity and a major public health concern in Bangladesh. In our study, animal-related injuries were common in rural Bangladesh, with a morbidity rate of 1635.3 injuries per 100000 populations. Most of the animal-related injuries were caused by hornets/wasps/bees stings (67\%). Males were at higher odds of having animal-related injuries than females. Animal-related injuries were more common in children and the working population, mainly among those involved in agriculture. Education and SES had an inverse relationship with the odds of having animal injuries. In addition, more than $72 \%$ injuries occurred during the rainy season. More than 35\% injuries occurred by provoking the animal or during feeding/ using for work. More than $81 \%$ victims did not require hospitalisation.

Increased risk among males compared with the females has been previously reported by the WHO and in other 
Table 1 Fatal and non-fatal animal-related injury rates (per 100 000) by sociodemographic characteristics

\begin{tabular}{|c|c|c|c|c|c|}
\hline \multirow[b]{2}{*}{ Characteristics/variables } & \multirow[b]{2}{*}{$\begin{array}{l}\text { Total population } \\
(\mathrm{N} \%)\end{array}$} & \multicolumn{2}{|c|}{$\begin{array}{l}\text { Fatal animal-related injury } \\
(n=8)\end{array}$} & \multicolumn{2}{|c|}{$\begin{array}{l}\text { Non-fatal animal-related injury } \\
(n=9563)\end{array}$} \\
\hline & & $\mathrm{n}=8$ & $\begin{array}{l}\text { Rate/100 000/year } \\
\text { (95\% Cl) }\end{array}$ & $\mathrm{n}=9563$ & Rate/100 000/year $(95 \% \mathrm{Cl})$ \\
\hline \multicolumn{6}{|l|}{ Sex } \\
\hline Male & $\begin{array}{l}567674 \\
(48.5)\end{array}$ & 5 & $\begin{array}{l}0.9 \\
(0.4 \text { to } 2.1)\end{array}$ & 5215 & $\begin{array}{l}1837.3 \\
(1803.0 \text { to } 1873.0)\end{array}$ \\
\hline \multicolumn{6}{|l|}{ Age group } \\
\hline$<1$ years & $\begin{array}{l}22141 \\
(1.9)\end{array}$ & - & - & 20 & $\begin{array}{l}92.6 \\
(59.8 \text { to } 143.5)\end{array}$ \\
\hline $1-5$ years & $\begin{array}{l}90523 \\
(7.7)\end{array}$ & 1 & $\begin{array}{l}1.1 \\
(0.2 \text { to } 6.3)\end{array}$ & 387 & $\begin{array}{l}843.6 \\
\text { (763.9 to } 931.9)\end{array}$ \\
\hline \multicolumn{6}{|l|}{ Level of education } \\
\hline No education & $\begin{array}{l}295314 \\
(25.3)\end{array}$ & 4 & $\begin{array}{l}1.4 \\
(0.5 \text { to } 3.5)\end{array}$ & 3344 & $\begin{array}{l}1132.4 \\
(1095.0 \text { to } 1171.0)\end{array}$ \\
\hline Primary & $\begin{array}{l}407923 \\
(34.9)\end{array}$ & 4 & $\begin{array}{l}1.0 \\
(0.4 \text { to } 2.5)\end{array}$ & 3701 & $\begin{array}{l}907.3 \\
(878.6 \text { to } 936.8)\end{array}$ \\
\hline Secondary and above & $\begin{array}{l}353531 \\
(30.2)\end{array}$ & - & - & 2110 & $\begin{array}{l}1048.7 \\
\text { (1001.9 to } 1097.3)\end{array}$ \\
\hline $\begin{array}{l}\text { Not applicable (U5 } \\
\text { children) }\end{array}$ & $\begin{array}{l}112664 \\
(9.6)\end{array}$ & 1 & $\begin{array}{l}0.9 \\
(0.2 \text { to } 5.0)\end{array}$ & 407 & $\begin{array}{l}361.3 \\
(327.5 \text { to } 398.5)\end{array}$ \\
\hline $\begin{array}{l}\text { Unskilled/domestic } \\
\text { (unskilled) }\end{array}$ & $\begin{array}{l}24520 \\
(2.1)\end{array}$ & - & - & 227 & $\begin{array}{l}925.8 \\
(813.4 \text { to } 1054.0)\end{array}$ \\
\hline $\begin{array}{l}\text { Rickshaw/bus (transport } \\
\text { worker) }\end{array}$ & $\begin{array}{l}17037 \\
(1.5)\end{array}$ & - & - & 120 & $\begin{array}{l}704.4 \\
(589.4 \text { to } 841.5)\end{array}$ \\
\hline Students & $\begin{array}{l}312537 \\
(26.7)\end{array}$ & 2 & $\begin{array}{l}0.6 \\
(0.2 \text { to } 2.3)\end{array}$ & 2344 & $\begin{array}{l}749.8 \\
(720.3 \text { to } 780.8)\end{array}$ \\
\hline $\begin{array}{l}\text { Retired/unemployed/ } \\
\text { housewife }\end{array}$ & $\begin{array}{l}408583 \\
(35.0)\end{array}$ & 1 & $\begin{array}{l}0.2 \\
(0.04 \text { to } 1.4)\end{array}$ & 3518 & $\begin{array}{l}861.0 \\
(833.2 \text { to } 889.8)\end{array}$ \\
\hline Children & $\begin{array}{l}144454 \\
(12.4)\end{array}$ & 1 & $\begin{array}{l}0.7 \\
(0.1 \text { to } 4.0)\end{array}$ & 621 & $\begin{array}{l}429.9 \\
(397.5 \text { to } 465.0)\end{array}$ \\
\hline Others & $\begin{array}{l}5948 \\
(0.5)\end{array}$ & 2 & $\begin{array}{l}33.6 \\
(9.2 \text { to } 122.5)\end{array}$ & 65 & $\begin{array}{l}1092.8 \\
(858.4 \text { to } 1390.0)\end{array}$ \\
\hline
\end{tabular}

U5, under-five.

\begin{tabular}{|c|c|c|c|c|}
\hline \multirow[b]{2}{*}{ Marital status } & \multirow[b]{2}{*}{$\begin{array}{l}\text { Total population } \\
\text { (N \%) }\end{array}$} & \multicolumn{2}{|c|}{$\begin{array}{l}\text { Fatal animal-related injury } \\
(\mathrm{n}=08)\end{array}$} & $\begin{array}{l}\text { Non-fatal animal-related injury } \\
(\mathrm{n}=9563)\end{array}$ \\
\hline & & $n=8$ & $\begin{array}{l}\text { Rate/100 000/year } \\
(95 \% \mathrm{Cl})\end{array}$ & $n=8$ \\
\hline Married & $\begin{array}{l}5671206 \\
(48.8)\end{array}$ & 4 & $\begin{array}{l}0.7 \\
\text { (0.3 to } 1.8)\end{array}$ & $\begin{array}{l}984.6 \\
\text { (959.3 to } 1011.0)\end{array}$ \\
\hline
\end{tabular}


Table 1 Continued

\begin{tabular}{|c|c|c|c|c|c|}
\hline \multirow[b]{2}{*}{ Marital status } & \multirow[b]{2}{*}{$\begin{array}{l}\text { Total population } \\
\text { (N \%) }\end{array}$} & \multicolumn{2}{|c|}{$\begin{array}{l}\text { Fatal animal-related injury } \\
(n=08)\end{array}$} & \multicolumn{2}{|c|}{$\begin{array}{l}\text { Non-fatal animal-related injury } \\
(\mathrm{n}=9563)\end{array}$} \\
\hline & & $n=8$ & $\begin{array}{l}\text { Rate/100 000/year } \\
(95 \% \mathrm{Cl})\end{array}$ & \multicolumn{2}{|c|}{$n=8$} \\
\hline Never-married & $\begin{array}{l}227319 \\
(19.4)\end{array}$ & 2 & $\begin{array}{l}0.9 \\
(0.2 \text { to } 3.2)\end{array}$ & 1261 & $\begin{array}{l}554.7 \\
(525.0 \text { to } 586.1)\end{array}$ \\
\hline $\begin{array}{l}\text { Widowed/divorced/ } \\
\text { separated }\end{array}$ & $\begin{array}{l}59033 \\
(5.1)\end{array}$ & - & - & 531 & $\begin{array}{l}899.5 \\
(826.5 \text { to } 978.9)\end{array}$ \\
\hline \multicolumn{6}{|l|}{ Wealth quantile } \\
\hline Lowest & $\begin{array}{l}211601 \\
(18.1)\end{array}$ & 3 & $\begin{array}{l}1.4 \\
(0.5 \text { to } 4.2)\end{array}$ & 2019 & $\begin{array}{l}954.2 \\
\text { (913.6 to } 996.5)\end{array}$ \\
\hline High & $\begin{array}{l}247716 \\
(21.2)\end{array}$ & 2 & $\begin{array}{l}0.8 \\
(0.2 \text { to } 2.9)\end{array}$ & 1943 & $\begin{array}{l}784.4 \\
\text { (750.4 to } 819.9)\end{array}$ \\
\hline Highest & $\begin{array}{l}253210 \\
(21.7)\end{array}$ & - & - & 1608 & $\begin{array}{l}635.1 \\
(604.8 \text { to } 666.7)\end{array}$ \\
\hline \multicolumn{6}{|l|}{ Subdistrict } \\
\hline Matlab North & $\begin{array}{l}265897 \\
(22.7)\end{array}$ & 2 & $\begin{array}{l}0.8 \\
(0.2 \text { to } 2.7)\end{array}$ & 1849 & $\begin{array}{l}695.4 \\
(664.5 \text { to } 727.7)\end{array}$ \\
\hline Matlab South & $\begin{array}{l}209772 \\
(18.0)\end{array}$ & - & - & 1134 & $\begin{array}{l}540.6 \\
(510.1 \text { to } 572.9)\end{array}$ \\
\hline Chandpur Sadar & $\begin{array}{l}128356 \\
(11.0)\end{array}$ & - & - & 259 & $\begin{array}{l}201.8 \\
(178.7 \text { to } 227.9)\end{array}$ \\
\hline Daudkandi & $\begin{array}{l}28373 \\
(2.4)\end{array}$ & - & - & 165 & $\begin{array}{l}581.5 \\
(499.5 \text { to } 676.9)\end{array}$ \\
\hline
\end{tabular}

studies. ${ }^{3}$ 15-17 Males are predominantly involved in agriculture in rural Bangladesh which increases their exposure to animals and insects in the physical environment.

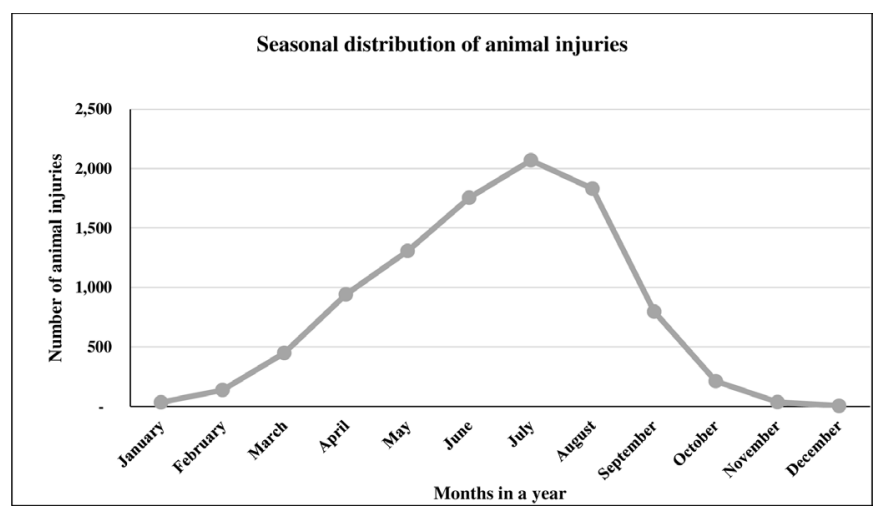

Figure 1 Non-fatal animal injuries over a 1 year period.
Additionally, younger men exhibit risk taking behaviour, which might entail provoking an animal. ${ }^{34}$ Rice, jute and tea are common agricultural produce in rural Bangladesh and attract rodents, which are prey for snakes and other non-domesticated animals. ${ }^{78-21}$ During farming, animalrelated injury is a major occupational injury in the USA and other high-income countries and lack of knowledge has been identified as one of the key reasons. ${ }^{22-25}$ Severe injuries and even deaths may occur from large animals, such as horses, bulls and swine. In addition to farmers, other occupations such as veterinarians, cowboys, animal caretakers, pet store operators and even researchers are at risk of trauma or zoonotic infections due to the nature of their work. ${ }^{22-25}$

As seen in this study, past studies have shown that the adult population above 18 years of age is most commonly affected by animal injuries — the most economically 

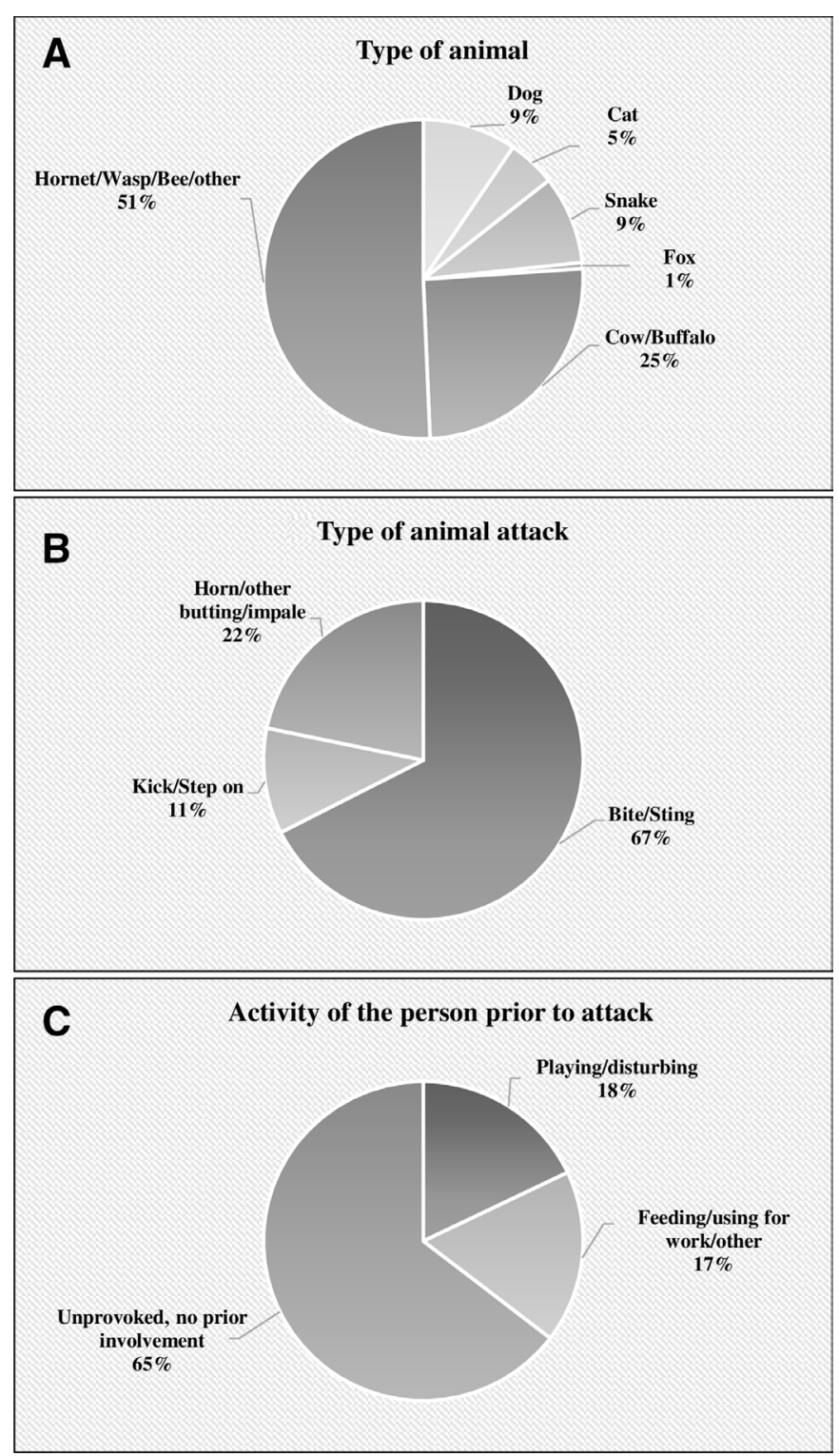

Figure 2 Factors associated with fatal and non-fatal animal injuries: (a) types of animals that caused an injury, (b) type of animal attack, (c) activity of the person prior to animal attack.

active group of the society that is also most exposed to hazardous environmental and occupational injuries. ${ }^{46-28}$ Another study found that individuals with no or little education are at higher risk for animal-related injury similar to results seen in our study. ${ }^{22}$ Contrary to these findings, one hospital-based study reported peak age of incidence of dog bites among children 15 years of age and below. ${ }^{9}$ Young children can be exposed to street dogs

Table 2 Injury severity index for non-fatal animal-related injuries

\begin{tabular}{lcc}
\hline Injury severity & $\mathbf{N}$ & Frequency (\%) \\
\hline Low & 7801 & 81.6 \\
Medium & 1183 & 12.4 \\
High & 579 & 6.1 \\
\hline
\end{tabular}

during play hours thus increasing their risk of animal injury.

Most of the non-fatal animal-related injuries occurred typically in the rainy season as venomous animals mostly appear around this time of the year. ${ }^{23}$ According to Wide-Ranging Online Data for Epidemiologic Research database, USA, most of the fatalities occur as a result of unexpected injury by the farm animals, bees, wasps or hornet stings, and dog attacks also. ${ }^{24}$ This study shows the highest rate $(51 \%)$ of animal-related injuries by the hornets/wasps/bees sting. On the other hand, few studies have also identified insect stings as a potential cause of animal-related injury. ${ }^{3922-24}$ WHO reports highest occurrence ( $76 \%$ to $94 \%$ ) of dog bites is in lowand middle-income countries (LMICs) and Bangladesh is ranked third among countries where rabies is endemical. Playing, feeding and provoked activities are recognised as common prior activities in this study and related results were found in other studies. ${ }^{1} 2529$

Most injury epidemiology studies are based on facilitybased surveillance data. The strength of our study is a large population-based sample size of about 1.17 million people providing stronger estimates on the prevalence of animal injuries in Bangladesh. Yet, this study also has some limitations. We cannot generalise the results to the entire country as the study was conducted in rural settings of Bangladesh only and the risk factors for urban settings might vary. However, our study findings may be generalisable to similar settings in other LMICs. In addition, the non-fatal animal-related injury rates may be underreported due to challenges in data collection, recall and selection (purposively selected) bias, ${ }^{11}$ stigmatisation and for family punitive reasons (especially children and adolescent group) or to accompany the census data collection. Additionally, the lack of year-round statistics on the burden of animal-related injuries introduces bias in the findings of this study and should be interpreted with caution when considering the seasonal variations of animal-related injuries.

This study suggests that the prevalence of animalrelated morbidities was high in rural areas, posing a serious public health problem in Bangladesh especially among the high-risk individuals such as males, school and productive age groups, and individuals from lower socioeconomic status. Findings also suggest that, animal-related injury linked to agriculture is a major occupational hazard in rural Bangladesh, and injury from unsafe interactions with domesticated animals is a major risk for young children. Strategies like education programmes to educate farmers in first aid, or encouraging parents to use cots and nets for their children that have already helped to reduce animal-related injuries in other LMICs can be developed for preventing animal-related injuries in Bangladesh. ${ }^{30}$ Implementation research on community awareness may support the development of a national strategy. We need further research to identify and accurately describe the actual burden of animal-related injuries on a national level 
Table 3 Unadjusted and adjusted analysis of non-fatal animal-related injury by age group, sex, education, occupation, marital status and socioeconomic status quintiles

\begin{tabular}{|c|c|c|c|c|}
\hline \multirow[b]{2}{*}{ Characteristics/variables } & \multicolumn{4}{|c|}{ Non-fatal animal-related injury } \\
\hline & OR unadjusted & $95 \% \mathrm{Cl}$ & OR adjusted & $95 \% \mathrm{Cl}$ \\
\hline \multicolumn{5}{|l|}{ Sex } \\
\hline Male & Reference & & Reference & \\
\hline Female & 0.8 & 0.7 to 0.8 & 0.7 & 0.6 to 0.7 \\
\hline \multicolumn{5}{|l|}{ Age group } \\
\hline$<1$ year & 0.1 & 0.1 to 0.2 & 0.2 & 0.1 to 0.3 \\
\hline 1-4 year & 0.5 & 0.4 to 0.5 & 0.8 & 0.6 to 0.9 \\
\hline $5-17$ year & 0.9 & 0.8 to 0.9 & 1.1 & 0.9 to 1.3 \\
\hline 18 years and above & Reference & & Reference & \\
\hline \multicolumn{5}{|l|}{ Level of education } \\
\hline No education & Reference & & Reference & \\
\hline Primary & 0.8 & 0.7 to 0.8 & 1 & 0.9 to 1.1 \\
\hline Secondary and above & 0.5 & 0.4 to 0.6 & 0.8 & 0.7 to 0.9 \\
\hline Not applicable (U5 children) & 0.3 & 0.2 to 0.4 & (omitted) & \\
\hline \multicolumn{5}{|l|}{ Occupation } \\
\hline Agriculture & Reference & & Reference & \\
\hline Business & 0.5 & 0.4 to 0.6 & 0.7 & 0.6 to 0.8 \\
\hline Skilled labour (professional) & 0.3 & 0.3 to 0.4 & 0.5 & 0.4 to 0.5 \\
\hline Unskilled/domestic (unskilled) & 0.8 & 0.5 to 0.8 & 0.8 & 0.7 to 0.9 \\
\hline Rickshaw/bus (transport worker) & 0.4 & 0.3 to 0.5 & 0.5 & 0.4 to 0.6 \\
\hline Students & 0.5 & 0.4 to 0.5 & 0.9 & 0.8 to 1.0 \\
\hline Retired/unemployed/ housewife & 0.6 & 0.5 to 0.6 & 0.9 & 0.8 to 1.0 \\
\hline Children & 0.3 & 0.2 to 0.3 & 0.7 & 0.6 to 0.8 \\
\hline Others & 0.7 & 0.5 to 0.9 & 0.8 & 0.6 to 1.0 \\
\hline \multicolumn{5}{|l|}{ Marital status } \\
\hline Married & Reference & & Reference & \\
\hline Never married & 0.5 & 0.5 to 0.6 & 0.5 & 0.5 to 0.6 \\
\hline Widowed/divorced/separated & 0.9 & 0.8 to 1.0 & 1 & 0.9 to 1.1 \\
\hline Children (<12 years) & 0.7 & 0.6 to 0.7 & 0.7 & 0.6 to 0.8 \\
\hline \multicolumn{5}{|l|}{ Wealth quantile } \\
\hline Lowest & Reference & & Reference & \\
\hline Low & 1 & 0.9 to 1.1 & 1 & 0.9 to 1.1 \\
\hline Middle & 0.8 & 0.7 to 0.9 & 0.9 & 0.9 to 1.1 \\
\hline High & 0.8 & 0.7 to 0.9 & 1 & 0.9 to 1.1 \\
\hline Highest & 0.7 & 0.6 to 0.7 & 0.9 & 0.8 to 1.0 \\
\hline \multicolumn{5}{|l|}{ Subdistrict } \\
\hline Matlab North & Reference & & Reference & \\
\hline Matlab South & 0.8 & 0.7 to 0.8 & 0.7 & 0.7 to 0.9 \\
\hline Chandpur Sadar & 0.3 & 0.2 to 0.4 & 0.3 & 0.2 to 0.3 \\
\hline Raiganj & 3.9 & 3.6 to 4.1 & 3.6 & 3.4 to 3.9 \\
\hline Sherpur & 1.1 & 1.0 to 1.2 & 1 & 0.9 to 1.1 \\
\hline Monohardi & 1.2 & 1.1 to 1.3 & 1.2 & 1.1 to 1.3 \\
\hline Daudkandi & 0.8 & 0.7 to 0.9 & 0.8 & 0.7 to 0.9 \\
\hline
\end{tabular}

U5, under-five. 
and to establish and implement effective animal-related injury prevention programmes across the country.

\section{Twitter Md Al Amin Bhuiyan @MD. Al-Amin Bhuiyan}

Contributors $A A B, O A, A R$ and $P A$ conceived the paper, contributed to the data analysis and reviewed the final draft for intellectual content. $A A B$ wrote the initial drafts of the manuscript. PA contributed to the data analysis and reviewed multiple drafts of the manuscript for intellectual content. SW, QL and FR reviewed the final draft of the manuscript for intellectual content. All co-authors provided editing support in finalising the manuscript. In addition, we would like to thank Eric Schulman, Communications Specialist of Johns Hopkins International Injury Research Unit for assistance with English language editing.

Funding This research was a part of the 'Saving of Lives from Drowning (SoLiD) in Bangladesh' project. We thank Bloomberg Philanthropies for the financial support for this research activity. We thank all the respondents of the study for providing their valuable time by participating in the interviews. Our special thanks to all the data collectors, supervisors and data managers for their hard work in collecting and managing data.

Competing interests None declared.

Patient consent for publication Not required.

Ethics approval The study protocol was approved by the Ethics Committee of Johns Hopkins Bloomberg School of Public Health, Centre for Injury Prevention and Research, Bangladesh and International Centre for Diarrhoeal Disease and Research, Bangladesh, under the study Saving of Lives from Drowning (SoLiD), Bangladesh.

Provenance and peer review Not commissioned; externally peer reviewed.

Data availability statement Data are available in a public, open access repository. Data are available upon reasonable request. All data relevant to the study are included in the article or uploaded as supplementary information.

Open access This is an open access article distributed in accordance with the Creative Commons Attribution Non Commercial (CC BY-NC 4.0) license, which permits others to distribute, remix, adapt, build upon this work non-commercially, and license their derivative works on different terms, provided the original work is properly cited, appropriate credit is given, any changes made indicated, and the use is non-commercial. See: http://creativecommons.org/licenses/by-nc/4.0/.

ORCID iDs

Md Al Amin Bhuiyan http://orcid.org/0000-0001-7385-0864

Qingfeng Li http://orcid.org/0000-0002-6390-6921

\section{REFERENCES}

1 Ramos JM, Melendez N, Reyes F, et al. Epidemiology of animal bites and other potential rabies exposures and anti-rabies vaccine utilization in a rural area in southern Ethiopia. Ann Agric Environ Med 2015;22:76-9.

2 Kennedy SA, Stoll LE, Lauder AS. Human and other mammalian bite injuries of the hand: evaluation and management. J Am Acad Orthop Surg 2015;23:47-57.

3 World Health Organization. Fact sheet on animal bites. fact sheet. WHO, 2018.

4 Gosavi S, Deshmukh P. Epidemiology of animal injuries: a community based study from rural area of Maharashtra. JMR 2015;1:18-21.

5 Medeiros IMSaconato H, Cochrane Wounds Group. Antibiotic prophylaxis for mammalian bites. Cochrane Database Syst Rev $2001 ; 1$.
6 Kabeta T, Deresa B, Tigre W, et al. Knowledge, attitudes and practices of animal bite victims attending an Anti-rabies health center in Jimma town, Ethiopia. PLoS Negl Trop Dis 2015;9:e0003867.

7 Hossain J, Biswas A, Rahman F, et al. Snakebite epidemiology in Bangladesh-A national community based health and injury survey. Health 2016;08:479-86.

8 Xuan BHN, Mai HL, Thi TXN, et al. Swarming hornet attacks: shock and acute kidney injury--a large case series from Vietnam. Nephrology Dialysis Transplantation 2010;25:1146-50.

9 Ghosh S, Chowdhury S, Haider N, et al. Awareness of rabies and response to dog bites in a Bangladesh community. Vet Med Sci 2016;2:161-9.

10 Rahman R, Faiz MA, Selim S, et al. Annual incidence of snake bite in rural Bangladesh. PLoS Negl Trop Dis 2010;4:e860.

11 Hyder $\mathrm{AA}$, Alonge $\mathrm{O}, \mathrm{He} \mathrm{S}$, et al. A framework for addressing implementation gap in global drowning prevention interventions: experiences from Bangladesh. J Health Popul Nutr 2014;32:564-76.

12 Hyder AA, Alonge O, He S, et al. Saving of children's lives from drowning project in Bangladesh. Am J Prev Med 2014;47:842-5.

13 Alonge O, Agrawal P, Talab A, et al. Fatal and non-fatal injury outcomes: results from a purposively sampled census of seven rural subdistricts in Bangladesh. Lancet Glob Health 2017;5:e818-27.

$14 \mathrm{He} \mathrm{S}$, Alonge O, Agrawal P, et al. Epidemiology of burns in rural Bangladesh: an update. Int J Environ Res Public Health 2017;14:381.

15 Esmaeilzadeh F, Rajabi A, Vahedi S, et al. Epidemiology of animal bites and factors associated with delays in initiating post-exposure prophylaxis for rabies prevention among animal bite cases: a population-based study. J Prev Med Public Health 2017;50:210-6.

16 Khazaei S, Rezaeian S, Soheylizad M. Factors associated with delay in post-exposure prophylaxis in bitten people. Med J Islam Repub Iran 2014;28:e69446.

17 Gautret P, Le Roux S, Faucher B, et al. Epidemiology of urban dog-related injuries requiring rabies post-exposure prophylaxis in Marseille, France. Int $J$ Infect Dis 2013;17:e164-7.

18 McLeod L. Feeding snakes frozen mice and other prey, 2018.

19 Williams D, Gutiérrez JM, Harrison R, et al. The global snake bite initiative: an antidote for snake bite. The Lancet 2010;375:89-91.

20 B R H, L H, A J L, et al. A study on the clinico-epidemiological profile and the outcome of snake bite victims in a tertiary care centre in southern India. J Clin Diagn Res 2013;7:122-6.

21 Monteiro FN, Kanchan T, Bhagavath P, et al. Clinico-epidemiological features of viper bite envenomation: a study from Manipal, South India. Singapore Med J 2012;53:203-7.

22 Gilyoma JM, Mabula JB, Chalya PL. Animal-related injuries in a resource-limited setting: experiences from a tertiary health institution in northwestern Tanzania. World J Emerg Surg 2013;8.

23 de Oliveira HFA, da Costa CF, Sassi R. Injuries caused by venomous animals and folk medicine in farmers from Cuité, state of Paraiba, northeast of Brazil. Rev Bras Epidemiol 2013;16:633-43.

24 Langley RL, Hunter JL. Occupational fatalities due to animal-related events. Wilderness Environ Med 2001;12:168-74.

25 Hakan K, Demirci S. Livestock-Handling Related Injuries and Deaths. In: Livestock production, 2012.

26 Cornelissen JMR, Hopster H. Dog bites in the Netherlands: a study of victims, injuries, circumstances and aggressors to support evaluation of breed specific legislation. Vet J 2010;186:292-8.

27 Bernardo LM, Gardner MJ, O'Connor J, et al. Dog bites in children treated in a pediatric emergency department. Journal for Specialists in Pediatric Nursing 2000;5:87-95.

28 Mondal SP, Yamage M. A retrospective study on the epidemiology of anthrax, foot and mouth disease, haemorrhagic septicaemia, peste des petits ruminants and rabies in Bangladesh, 2010-2012. PLOS One 2014;9:e104435.

29 Chen Y, Gao Y, Zhou L, et al. A comparative study of dog- and catInduced injury on incidence and risk factors among children. Int $J$ Environ Res Public Health 2016;13:1079.

30 Alirol E, Sharma SK, Bawaskar HS, et al. Snake bite in South Asia: a review. PLoS Negl Trop Dis 2010;4:e603. 